\title{
Editorial
}

\section{Preeclampsia after the Seven Quantum Leap Prediction}

\author{
Johanes C. Mose
}

Preeclampsia is the disease of decades. During the 20th century there were seven quantum leaps or discoveries recorded. First, the discovery of the inflatable armband permitting to measure blood pressure in 1896. Second, the discovery that eclamptic (convulsions), and later "pre"eclamptic (proteinuria) women presented hypertension in 1897 and confirmed in 1903, the discovery of the hypertensive disorders of pregnancy. Third, the eight major textbooks published all along the 20th century by delineating risk factors of preeclampsia with the concept of "preeclampsia, disease of primigravidae". Fourth, the discovery in the 1970's that human trophoblast implantation was far deeper than in other mammalian species. Fifth, and a major step forward, description at the end of the 1980's that the maternal syndrome in preeclampsia (glomeruloendotheliosis, HELLP syndrome, eclampsia) could be unified in a global endothelial cell inflammation. Sixth, the epidemiological descriptions in the 1970-1990's that indeed preeclampsia was a disease of first pregnancies at the level of a couple ("primipaternity concept"), leading to an explosion in immunological research in the last decade, beginning in 1998. Seventh and finally, in the search for the "factor X" explaining the vascular inflammation in preeclamptic women (inositol phospho glycans P-type were described in 2000, while soluble Flt-1 and S-endoglins have been clearly predicted since 1997). The majority of the seeds or findings have been grounded or realized in the 20th century. Indeed, for preeclampsia, the 20th century has been le "Siècle des Lumières" (the Enlightenment). ${ }^{1}$

So, where are we now? Have we won the war yet?In reality, we as humankind are living in the same one house named "The World" but with highly diverse in way of life, culture and destiny. We are different in almost every aspect of life, so are the differences in the prevalence, morbidity and mortality of preeclampsia.Although there is likely to accept the dictum that "Eclampsia is a disease of the past", but at the same time stroke, pulmonary oedema or cardiovascular complications are becoming common complications leading to maternal death of severe preeclampsia. ${ }^{2-4}$

In the developed world, where health facilities including emergent caesarean delivery and wellprovided health assurance are available, the burden of morbidity and mortality due to preeclampsia are reasonably lighter compared to the other part of the world.

Let us together hand in hand as the family of the same world, collaborate against this mother's killer number one. Implementation of human genome project into personalised medicine, dissemination of Colabs program, international collaborations, training program and workshops, sharing experiences, socialising guidelines and standard protocols, etc are among others kind of activitieswhich has to be enhanced in the years to come.We are still in the middle of the battlefield. 


\section{References}

1. Robillard PY, Dekker G, Chaouat G, Le Bouteiller P, Scioscia M, Hulsey TC. Preeclampsia and the 20th century: "Le siècle des Lumières". Preg Hypertens, 2018;13:107-9

2. Magee LA, Pels A, Helewa M, Rey E, von Dadelszen P, Canadian Hypertensive Disorders of Pregnancy (HDP) Working Group. Diagnosis, evaluation, and management of the hypertensive disorders of pregnancy.Pregnancy Hypertension: Int J Women's Cardiovascular Health 2014; 4: 105-45

3. Henderson JT, Thompson JH, Brittany U. Burda, BU, Cantor A. Preeclampsia Screening Evidence Report and Systematic Review for the US Preventive Services Task Force. JAMA 2017;31:1668-83.

4. Brown MA, Magee LA, Kenny LC, Karumanchi SA, McCarthy FP, Saito, Hall DR, Warren CE, Adoyi G, Ishaku S, the International Society for the Study of Hypertension in Pregnancy (ISSHP). The Hypertensive disorders of pregnancy: ISSHP classification, diagnosis \& management recommendations for international practice. Preg Hypertens, 2018; 13: 291-31. 